\title{
Bone mesh fixation for the treatment of suprailiac hernia. Report of two cases
}

\author{
Eventración suprailíaca: reparación con malla fijada a hueso. Reporte de dos casos
}

María E. Muriel1*, Mayra R. Peralta ${ }^{1}$, Marcelo Arias $^{2}$, Ignacio Pioli ${ }^{3}$, and Carlos P. Carmignani ${ }^{1}$

${ }^{1}$ Department of General Surgery; ${ }^{2}$ Department of Plastic Surgery; ${ }^{3}$ Department of Traumatology and Orthopedics. Sanatorio Allende Cerro de las Rosas, Córdoba, Argentina

\begin{abstract}
Hernias of the lateral abdominal wall are a rare entity. In most cases, they occur after surgery or trauma. We present two cases of lumbar hernia: the first one after iliac bone grafting and the second one after muscular tearing by the seatbelt during a car accident. Both cases were successfully repaired using a propylene mesh with bone fixation.
\end{abstract}

Key words: Bone injert. Iliac bone. Incisional hernia. Lumbar hernia.

\section{Resumen}

Las eventraciones de la pared lateral del abdomen son poco frecuentes. Pueden ser posquirúrgicas o causadas por agentes traumáticos. Se presentan dos casos de eventración lumbar: el primero tras una resección ósea por autoinjerto de cresta ilíaca y el segundo por desinserción muscular por cinturón de seguridad secundaria a un accidente en la vía pública. Ambos fueron resueltos quirúrgicamente con colocación de una malla de polipropileno fijada a hueso.

Palabras clave: Injerto óseo. Cresta ilíaca. Hernia incisional. Eventración lumbar.

\section{Introduction}

Hernias of the lateral wall of the abdomen are infrequent. Patients usually have a history of surgery or trauma. The incidence of this type of abdominal hernia varies from 5 to $9 \%^{1-5}$ for the first cause and even more infrequent for the former.

Pre-operative evaluation should include computed tomography (CT) scan to assess anatomic features (sac, size, content, and boundaries) that may help at the time of planning the surgical strategy $y^{2,5,6}$.
Due to the high rate of incarceration and strangulation that can reach $25 \%$ and $10 \%$, respectively, timely surgical repair is recommended (within 6 months from the time of diagnosis) ${ }^{1-5}$.

Two cases of lateral abdominal wall hernias that required bone mesh fixation are presented.

\section{Case 1}

A 67-year-old woman with a history of diabetes, obesity, deep venous thrombosis, and pulmonary

\section{Correspondence:}

*María E. Muriel

Ituzaingó, 1054

Córdoba Capital

C.P. 5000 , Córdoba, Argentina

E-mail: emimuriel10@hotmail.com
Date of reception: 14-08-2019

Cir Cir. 2020;88(S2):99-102

Date of acceptance: 17-06-2020

DOI: $10.24875 / C I R U .19001499$
Contents available at PubMed

www.cirugiaycirujanos.com

0009-7411/@ 2020 Academia Mexicana de Cirugía. Published by Permanyer. This is an open access article under the terms of the CC BY-NC-ND license (http://creativecommons.org/licenses/by-nc-nd/4.0/). 
emboli needed an iliac bone grafting for reconstruction of a fracture of femur and tibia. Five years after surgery, she complained of a lateral abdominal wall incisional hernia that was repaired without mesh. Five years after the first repair, she had a hernia recurrence. At that time, she had a second hernia repair, a propylene mesh was used. Ten years after the last intervention, she experienced a second recurrence.

Physical examination showed a protrusion on the right lateral wall of the abdomen, reducible that increased in size with Valsalva's maneuver. The patient had neither pain nor symptoms of intestinal occlusion.

Abdominal CT scan revealed a hernia in the lumbar fossa, protruding between the oblique muscles of the abdomen and the iliac bone, $4 \mathrm{~cm}$ in greatest diameter. The right colon was inside the hernia sac (Fig. 1).

One month after the first consultation, an open hernia repair with a propylene mesh was performed. The hernia sac was dissected up to its neck and it was opened anteriorly. The right colon was reintroduced into the abdominal cavity, and the hernia defect was closed using a running polyglactin number 1 suture. A $2 \mathrm{~mm}$ trepanation every $2 \mathrm{~cm}$ was performed on the iliac bone. The mesh was fixed using number 0 propylene sutures that were passed through the trepanations. A 15 by $15 \mathrm{~cm}$ propylene mesh was used to cover the defect with an extension of at least $2 \mathrm{~cm}$ over the edges (Fig. 2). Some extra fixation stiches were placed using the same material. A JacksonPratt $^{\circledR}$ (Cardinal Health, Dublin, Ohio,) drain was used. The patient had no post-operative complications. The discharge occurred within $48 \mathrm{~h}$. After 24 months of follow-up, no recurrence was registered.

\section{Case 2}

A 37-year-old lady had a tear of the muscles of the lateral abdominal wall generated by the seatbelt during a car accident. Six months after the collision, she complained of pain and a protrusion on the left flank.

Physical examination showed a big hernia on the left flank, reducible and without complication signs.

CT scan revealed a major hernia occupying the lateral and posterior wall of the abdomen with a $38 \mathrm{~mm}$ by $56 \mathrm{~mm}$ defect (Fig. 3).

The patient was operated 40 days after the consultation. An open hernioplasty with propylene mesh was performed. A big sac that reached beyond the superior edge of the iliac bone was dissected and completely resected (Fig. 4). Again, $2 \mathrm{~mm}$ trepanations were performed on the iliac bone to fix the mesh. In

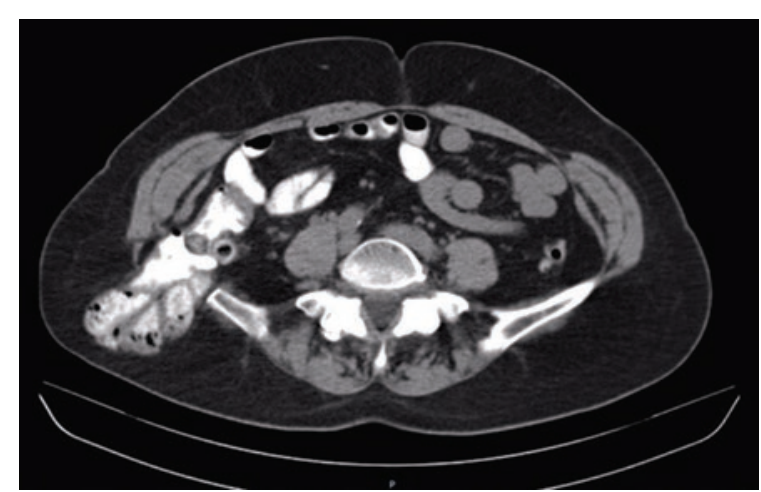

Figure 1. Axial computed tomography scan where abdominal hernia with colonic content can be seen.

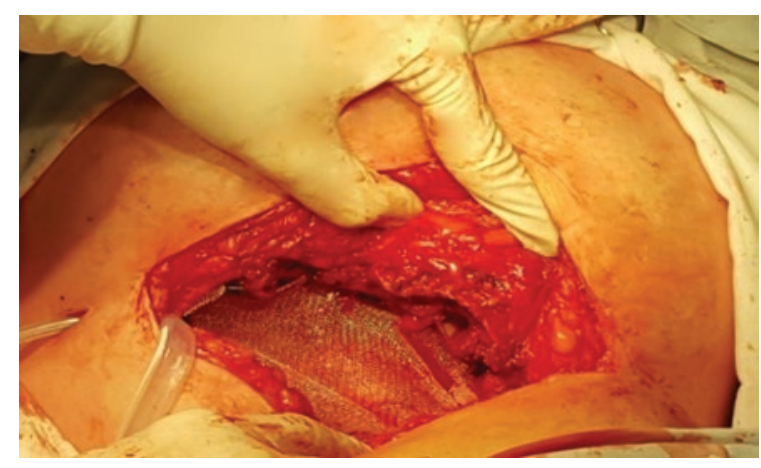

Figure 2. Mesh placed over the defect with bone fixation.

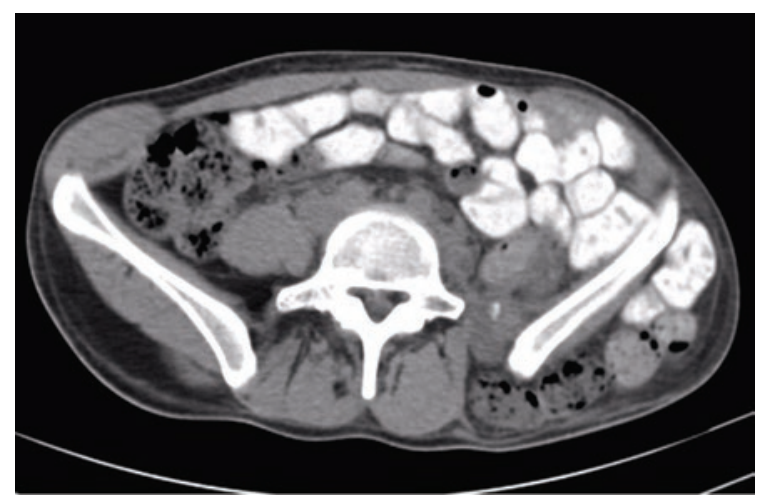

Figure 3. Axial computed tomography scan where lateral incisional is shown.

this case, a 15 by $15 \mathrm{~cm}$ bi-phasic Proceed ${ }^{\circledR}$ (Ethicon, New Brunswick, New Jersey) mesh was used, covering the defect with an extension of at least $2 \mathrm{~cm}$ over the edges. Propylene 0 stiches were used for mesh fixation to the abdominal wall (Figs. 5 y 6 ).

One year after this surgical procedure, the patient was involved in other accidents. This time she was hit by a van while trying to cross a street. As one of the 


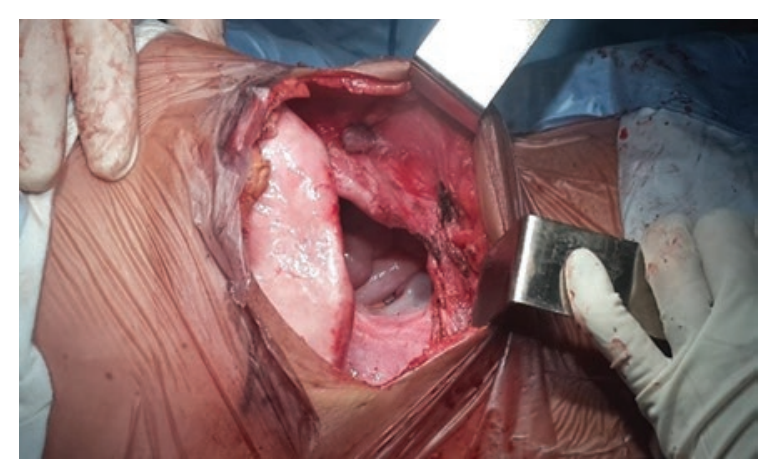

Figure 4. Wall defect.

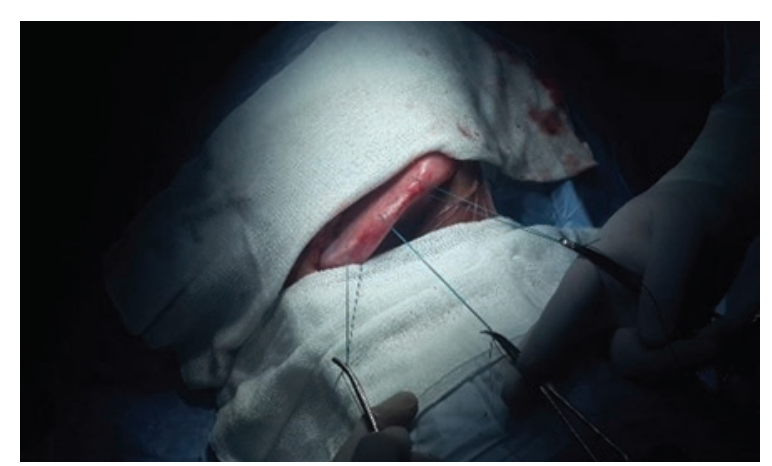

Figure 5. Bone trepanation.

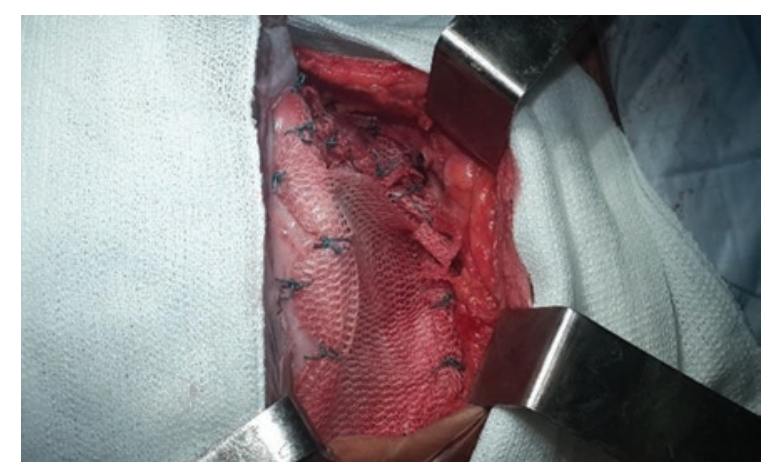

Figure 6. Mesh placed over the defect with bone fixation.

consequences of this accident, the known hernia appeared again.

After leaving the hospital, she went into a prolonged rehabilitation program. Once she was fit, a new intervention was planned. During surgery, we could observe that the mesh was still very well fixed to the bone, but she had weak muscular and aponeurotic layers around the defect. We decided to perform 3 more trepanations on the iliac bone to fix an extra Proceed $^{\circledR}$ mesh of 15 by $15 \mathrm{~cm}$. A Jackson Pratt ${ }^{\circledR}$ drain was left in place.
No complications nor recurrence were recorded at 26 months of follow-up.

\section{Discussion}

The hernia of the lateral wall of the abdomen is a rare entity that is more frequent in women ${ }^{2,4}$. Only 400 cases could be found in the literature ${ }^{3,5}$. The incidence of this kind of hernia varies from 5 to $9 \%$ when they are secondary to surgery and are even less frequent after trauma ${ }^{2-5}$. Older age, female gender, obesity, obstructive pulmonary disease, and previous surgery, especially kidney transplantation and iliac bone grafting, have been described as risk factors ${ }^{4,6}$.

Symptoms may appear long time after surgery or trauma (even after 10-15 years) ${ }^{2-5}$. The sac content may include omentum, kidney, spleen, large, or small bowel ${ }^{4,5}$.

The gold standard for diagnosis is CT scan. It allows a complete anatomical examination and a correct surgical planning ${ }^{2-5}$.

Anatomy of the lumbar area is complex, mostly due to the many muscular insertions that exist at this point. The lumbar area is comprised of the inferior edge of the twelfth rib and the iliac bone crest, interiorly by the erector spinae muscle and laterally by the external oblique muscle. This region is divided into two compartments. The superior lumbar triangle is delimited by the twelfth rib, the lumbocostal ligament and the serratus, the intern oblique muscle and the erector spinae muscle. The inferior lumbar triangle is delimited by the iliac crest, the external, and the internal oblique muscles. Both triangles are weak spots where congenital or acquired hernias might occur: they are called Grynfeltt and Petit, respectively ${ }^{3}$.

In this experience, atypical situations were presented since the normal anatomy is altered. In the first case, the Petit triangle was enlarged by the extraction of the iliac crest for bone grafting. Even though the herniation after this technique is still infrequent with an incidence of $5-7 \% \%^{7}$. In the second case, a tearing of the lateral abdominal wall muscles occurs during a car accident resulting in the enlargement of the inferior lumbar triangle. Then, the repair of this kind of hernias represents two different challenges: on the one hand, the closure of an anatomical defect considerably enlarged after surgery or trauma, on the other hand, facing a rare procedure, scarcely reported. Gluteal or lumbar muscle flaps ${ }^{8}$ so as the transference of the oblique muscle ${ }^{9}$ have been described in the literature. However, the success of these techniques 
depends on the size of the defect and the time between the hernia development and the repair since the muscles tend to retraction in this high tension area $^{3}$. In addition to this, the great range of motility that this region can provide goes from 0 to $20 \mathrm{~cm}$ from the flexion to the complete extension of the body ${ }^{10}$.

The placement of a big sized prosthetic mesh fixed to the bone and extending the edges of the defect is the most important issue to achieve a tension-free reconstruction, avoiding mesh migration, and then reducing at the least the chances of recurrence that might reach $25 \%$ 10,11.

Different options for the surgical approach could be used in this kind of hernias. The primary objectives, though, are the same as those for any abdominal hernia: reduction of the hernia, a tension-free closure of the defect, and wall reinforcement. Due to being such an infrequent entity, an open approach using bone fixation of a big mesh should be considered the procedure of choice. As presented in these cases, the mesh should extend the edges of the defect for at least $2 \mathrm{~cm}$, with bone fixation and suction drain to minimize the dead space left after the hernia reduction to minimize the risk of seroma formation ${ }^{5,11}$.

The laparoscopic approach has also been described where a better visualization of the iliac bone could be used for improved fixation of the mesh ${ }^{3,5}$. Nevertheless, this approach is technically demanding, difficult to reproduce, and could be risky since it increases the risk of visceral injury during the reduction of the $\mathrm{sac}^{5}$. Moreover, this approach needs bigger and far more expensive meshes (made safe for visceral contact).

\section{Conclusion}

Pre-operative evaluation by CT scan is useful for surgical planning. An open approach is recommended to ensure a secure fixation of the mesh to the bone that might provide enough resistance to avoid recurrence.

\section{Funding}

No financial support was provided for this investigation.

\section{Conflicts of interest}

The authors declare that there have no conflicts of interest.

\section{Ethical disclosures}

Protection of human and animal subjects. The authors declare that no experiments were performed on humans or animals for this study.

Confidentiality of data. The authors declare that they have followed the protocols of their work center on the publication of patient data.

Right to privacy and informed consent. The authors have obtained the written informed consent of the patients or subjects mentioned in the article. The corresponding author is in possession of this document.

\section{References}

1. Do MV, Richardson WS. Lumbar incisional hernia repair after iliac crest bone graft. Ochsner J. 2012;12:80-1.

2. Ravindra I, Avinash B. Hernia through an iliac crest bone graft site: a case report. IJSS Case Rep Rev. 2016;2:12-13.

3. Vagholkar J, Budhkar A, Gulati J. Lumbar incisional hernia repair following iliac bone graft harvest. J Case Rep. 2014;4:379-82.

4. Prabhu R, Kumar N, Shenoy R. lliac crest bone graft donor site hernia: not so uncommon. BMJ Case Rep. 2013;2013:bcr2013010386.

5. Aissat A, Mesbahi A, Habarek M, Bendjaballah M, Taieb M, Nait Slimane $\mathrm{N}$, et al. Right lumbar incisional hernia repair after iliac crest bone graft: a case report and literature review. Int J Surg Res. 2017;6:25-8

6. Fontaine V, Villeneuve P, Belzile E, Laflamme M. Hernia through an iliac crest bone graft harvest site: two cases treated differently. J Clin Case Rep. 2016;6:5.

7. Di Carlo I, Toro A, Sparatore F, Corsale G. Lumbar hernia repaired using a new technique. Am Surg. 2007;73:54-7.

8. Mayagoitia González JC, Cisneros Muñoz HA, Álvarez Quintero R, Bernal Gómez R, Manuel Guillén J. Manejo de las hernias lumbares de la pared abdominal. Seguimiento a mediano y largo plazo de sus resultados. Cir Gen. 2008;30:197-203.

9. Carbonell AM, Kercher KW, Sigmon L, Matthews BD, Sing RF, Kneisl JS, et al. A novel technique of lumbar hernia repair using bone anchor fixation. Hernia. 2005;9:22-5.

10. Radais F, Facy O, Ortega-Deballon P. Transiliac hernia. Am J Surg. 2011;201:e41-2.

11. Velchuru VR, Satish SG, Petri GJ, Sturzaker HG. Hernia through an iliac crest bone graft site: report of a case and review of the literature. Bull Hosp Joint Dis. 2006;63:166-8. 